\title{
My Stradivarius is Making Me Sick: A Luthier's Ethnography of Tradition and Injury
}

\author{
Ray Archee
}

\begin{abstract}
Why are musicians some of the most unhealthy of all the performing artists compared to singers, dancers, actors, performance artists, and public speakers? Is it their temperament, their longevity, their inherently weaker bodies, or some other factor? The author's background is as a luthier and guitar player. Using an ethnographic approach, this paper suggests that it some musicians' reliance on traditional instruments and old-fashioned practice habits that is causing physical health problems, and that this behaviour is largely due to conservatism, misunderstanding, and myth. It is argued that these attitudes need to be changed so that some musicians can remain healthy in order to function at an optimal level. Several recommendations are suggested.
\end{abstract}

Index Terms-Ethnography, luthier, guitar, injury, health.

\section{INTRODUCTION}

In addition to being an academic, my passion for the past 14 years has been in the construction and design of acoustic and electric guitars, in conjunction with being a guitar player for the past 40 years. I have been a student, apprentice, and research associate of the second largest guitar manufacturer in Australia, Gilet Guitars, which began making custom guitars in 1976. My range of custom-made instruments has included acoustic, classical, Flamenco, electric and archtop guitars.

During this time, my experience has included all manner of tasks from design, jig making, preparation of materials, construction, repair, and final finishing to meeting customers and teaching. Making a guitar consists of dozens of intricate tasks often involving fine measurements to hundredths of a millimeter. It also involves becoming skilled and proficient with a range of power tools, hand tools, glues, laminates, and spray techniques. My major interest has been making archtop guitars, some of which are now being played by top jazz players in Australia and USA. My mentors during this time were master luthier, Gerard Gilet and his colleagues with a combined experience of many decades. At this workshop, I have met and discussed luthiery problems with many friends, associates and clients. I have also met guitarists suffering from practice-related injuries and experienced "first-hand" (sic), similar problems.

Previously, in 1982 I suffered a debilitating right wrist injury that prevented me playing classical guitar for many years. During this time I sought help from doctors and specialists who varyingly diagnosed a ganglion, RSI and tendinitis but could not remedy my ailment. I changed to playing jazz guitar using a plectrum, and the wrist problem

Manuscript received August 9, 2017; revised November 10, 2017.

R. Archee is with Western Sydney University, Australia (e-mail: r.archee@westernsydney.edu.au). healed itself within a few years. However, I never played classical guitar in a concert again.

My problem was due to 1 . using a traditional right-hand or Segovia technique (excessively extended dorsal wrist position with a lateral rotation), 2. over-practising a Flamenco rasgueado technique. My cure came about from rest, changing my hand position, and playing many different kinds of guitars and styles of music. My wrist problems have never recurred, even after subsequent intensive study of Flamenco guitar.

However, many students of classical and other styles of guitar, and especially ( $80 \%$ of) orchestral string instrument players eventually suffer a range of bodily problems ranging from RSI and tendinitis to tingling and numbness in their arms, shoulders, hands and backs [1]. Many instrument players will seek medical help, or other therapies in order to overcome their ailments. Unfortunately, some players will continue to experience pain and perhaps depression, and a few will never seriously play again.

This article argues that physical injuries are inevitable if one repeats exactly the same movements on the same instrument for many hours every day. It suggests that the traditional design of musical instruments, especially the classical guitar and string family has exacerbated many of these physical problems. Playing the best violin in the world does not mean one can be a healthy violinist.

\section{TRaditions OF AUSTRALian LUTHIERY}

The luthier community in which I have participated usually valued traditional designs and materials above possible innovation. The workshop, located at Botany, Sydney stockpiled tried and tested Sitka Spruce, Australian Blackwood, Honduran Mahogany and Indian Rosewood as the main woods used to make acoustic guitars. The main instrument styles were all based on traditional American guitar companies - Martin and Gibson. The only surprising departure from tradition were the options of classical instruments, which could be made in the Spanish manner, or using contemporary Australian lattice-braced designs. However, the shapes of these carbon-fibre braced guitars were completely traditional.

There is no guild or association of Australian luthiers, but the Australia and New Zealand Luthiers' (online) Forum has very little to discuss when it comes to issues such as ergonomic innovation to avoid overuse injuries. Luthiers online as well as in person, tend only to discuss, consider and appreciate traditional woods, designs and processes.

Contemporary violin makers face a similar predicament. The design of the violin family has not changed substantially since the middle of the $19^{\text {th }} \mathrm{C}$. The most highly regarded 
instruments are from the Cremona school of Stradivarius and Guarneri, and have become extremely expensive. However, in several blind tests most people, including musicians cannot tell the difference between a Stradivarius and an excellent modern violin [2]. Nonetheless, vintage traditional instruments are still revered by musicians and the general public alike, with many accompanying scientific theories postulated to explain their supposedly ideal sound.

Acoustic steel-stringed guitars are predominantly an American invention, with classical nylon string guitars evolving from Europe. Both kinds of guitars also stem from the mid $19^{\text {th }} \mathrm{C}$, when only gut strings were available. Specifically, it was the strings made from nylon and steel, which were $20^{\text {th }} \mathrm{C}$ inventions, that firmly distinguished the design, construction and sound of the two main types of guitars.

\section{TRAdITIONS OF GUITARS AND STRING InSTRUMENTS}

The first modern guitars began with C.F. Martin in the USA in 1874 [3] and Antonio de Torres in Spain in 1852 [4]. While both makers owed debts to previous European makers of parlour guitars, lutes, vihuelas and the like, Martin and Torres established the shape, size and depth of the modern steel string and classical/Flamenco guitars that are played today. That is, the scale length and hence the overall length of the fretboard, plus the body shape resembling a female human torso were founded at these times. By increasing the scale and size of the instrument, guitars went from small instruments played in the home by mainly females to serious instruments able to be played in public arenas. At the time, the only other instruments able to play chords were keyboard instruments such as the piano and accordion.

The orchestral string instruments - violin, viola, cello and double bass - were descendants of the viol family - lira de braccio, rebec, and medieval fiddle. While there were earlier Italian violins, it was Antonio Stradivari (1644-1737) who is credited with finalising the shape and size of the modern violin by decreasing the belly arch, and widening the F-holes thus producing a louder concert violin. Eventual slight changes to scale length, bridge curvature and string angle added even more volume. Nineteenth century inventions of the chin rest (1820) and the shoulder rest (date unknown) firmly established the modern violin as it is played today.

As can be seen, orchestral string instruments reached their pinnacle of development over 150 years ago. The steel string guitar, made by Martin reached its highest point in the period between the world wars. Nylon string guitars, surprisingly seem to be still evolving because of the use of new materials such as carbon fibre, and Nomex.

Why has the design of the violin and guitar ceased to develop and evolve since these times? Is it really the case that perfection had been attained, or is it because few players wished to purchase an odd-looking violin, or guitar that may actually sound better, or prevent RSI?

\section{UNDESERVED REVERENCE FOR THE OLD AND VINTAGE}

We live in technological times arguably the fastest epoch of societal change since the industrial revolution. The electronic mass media, computers, and social media have come to dominate our every waking moment. We cannot imagine a world without being tethered to the Internet or our mobile devices. But antique objects in the form of furniture, paintings, books and artifacts remind us of another world - a time when fine craftsmanship was the norm, as opposed to mass production in third-world factories. A vintage guitar or violin that not only looks old but also sounds beautiful is the ultimate object of desire for many musicians, and collectors. The vintage instrument embodies old-world fascination together with a provenance of being played by other musicians who have bequeathed their music into the soul of the instrument. Marks, scratches, and dents add even more character and appeal.

In terms of guitar making, nothing could be further from the truth. The custom guitar, unlike the custom violin is a modern instrument. The vast majority of American guitars (and Spanish ones) have been manufactured in factories such as those built by Martin, Gibson and Fender. Hand-made, custom guitars represent a very small percentage of the American and European markets. The majority of desirable vintage guitars were usually made in a factory, where each step off the process was performed piecemeal by factory workers who never experienced a complete guitar from start to finish. These factories were streamlined to extract the utmost number of guitars from the given materials. Workers were expected to produce a targeted output per day, so mistakes were fairly common, and not rectified. Many production guitars possessed small mistakes due to human error that could not be seen from the outside but eventually need to be repaired.

Most vintage guitars that have come into my purview exhibit a range of problems, including buzzes, faulty bracing, poor glue joints, poor workmanship, bad finishes, incorrect geometry, and frets that were not correctly positioned. One of the worst examples of human error was a 1967 Guild thinline guitar bought from the original owner on ebay. The frets were not positioned in their correct locations meaning the guitar could not be tuned properly. The guitar was in perfect condition in an original case, but the factory had inserted all the frets in the wrong places.

Similar mistakes can occur in the custom world of Spanish guitars. After extensively researching and visiting most of the Madrid luthiers in 2010 the author purchased a wonderful sounding classical guitar from a renowned luthier for a good price. The guitar looked beautiful and sounded excellent, but possessed a slight but obvious mistake of two small witness marks at the end of the soundboard where there was differential vibration of the internal binding and the end block with the top. Over time these marks could produce cracks, but the ordinary player would never recognize this problem.

The same problems occur with violins to a greater or lesser degree. Flaws can occur in the choice of woods (grain orientation, runout, knots, colour, grain width), the type of varnish, the soundpost, the fingerboard, the tailpiece, the bridge, the pegs and the setup [5]. A vintage or custom instrument is no guarantee of an instrument being free from defects with factory instruments usually more likely to possess human errors since more humans have worked on their component parts. 


\section{InJuries AFFLiCting Musicians}

In the $19^{\text {th }} \mathrm{C}$, the medical community observed overuse injuries and called them occupational cramp or musicians' cramp. A more negative term was occupational neurosis (meaning of the brain) with two competing theories of origin. One was the theory that the problems stemmed from overuse of the brain, the second viewed the problem as coming from the muscles themselves [6]. In 1986, Australian research estimated around 20\% injury rate in Australian music performance schools rising to around $50 \%$ for eight symphony orchestras around the world when performers were between 30-35 years old [7].

The number of injuries that can afflict musicians are numerous and varied. Arguably it is percussionists who are at most risk of injury because of their aggressive habit of hitting other objects with hands or sticks. After drummers, the next level, at-risk, are the string family players. Guitarists should be included next because there are just so many of them. Guitars are certainly the most played instrument in the world, although no-one knows how many guitarists exist. If one assumes one in five people know how to play guitar chords, then that number is 1.4 billion; if one asks how many can play passably well, that number is much lower, probably around 50 million [8].

Although the medical diagnosis of injuries include a glossary of medical ailments affecting nerves, and soft tissues, the vast majority of injuries occur as a result of three activities or conditions: 1. playing a musical instrument, for 2 . too long, using the 3 . same technique. It is rare to find musicians' injuries that occurred as a once-off occurrence. One does not acquire RSI from a single practice session of Flight of the Bumblebee.

From my perspectives as a luthier and player, if one could significantly vary any one of the three conditions above, then this could minimize the risk of injury, or perhaps even eliminate it. Rank amateur musicians tend not to become injured because they do not practice enough to damage their bodies, but professionals must put in sufficient practice hours to learn their pieces, thus Condition 2. or practice time is not easily varied. The remaining conditions, the musical instrument and the same technique, are therefore the two variables that could offer assistance to the vast numbers of afflicted musicians. However, as will be seen, this is not an equitable contest in terms of published solutions.

Surprisingly, very similar injuries also affect luthiers themselves. Little research exists on afflictions from making instruments as opposed to playing them, but recent personal research with a closed Facebook group of 200 luthiers from all over the world reveals similar complaints. Roughly $25 \%$ of these luthiers report a variety of physical problems: rotator cuff, arthritis, tendonitis, back problems.

Practically every article or book on the subject of musicians' injuries largely examines good playing habits and suggests alternate techniques to avoid becoming injured [9], [10]. Tacitly, these authors are saying that there is something essentially wrong with the way in which a musician warms up, practises and performs on their chosen instrument. Very few authors discuss the design of traditional instruments themselves, or modifications to existing instruments. It is as if human beings must customize their bodies to the shapes and sizes of the violin and guitar with varying the design of the instrument unacknowledged as being the solution to injury.

In most specialized books on injury prevention, negligible attention is paid to the re-design of traditional musical instruments. A recent book spends just two paragraphs noting that "musical instruments were not designed with upper extremity ergonomics in mind" [11] then proceeds to quickly discuss the cost, availability, sound and acceptance of variations in traditional instruments. By definition, it seems injuries are the logical conclusion of intensively playing any traditional musical instrument.

\section{RE-DESIGNING THE VIOLIN}

There is some degree of interest in ergonomic instruments from musicians and certainly curiosity from the general public. While the vast majority of students learn on inexpensive, mass-produced instruments from third-world country factories, a few progress to traditional European and American instruments when they become serious players. It is not until these musicians experience injury however, that the thought of playing an ergonomic instrument becomes a reality.

The Chanot violin (1819) is possibly one of the first examples of an ergonomic violin. This vintage design combines an asymmetrical body with the structure of a guitar bridge. Chanot removed the tailpiece, and all sharp corners, streamlining the F-holes, and permitted easier left hand access to the upper register.

Joseph Chanot attempted to apply scientific principles to luthiery, not to assist injured musicians. His guitar-shaped violin was judged to be superior in tone to a Stradivarius, but his unusual design did not become popular in the $19^{\text {th }} \mathrm{C}$ [12].

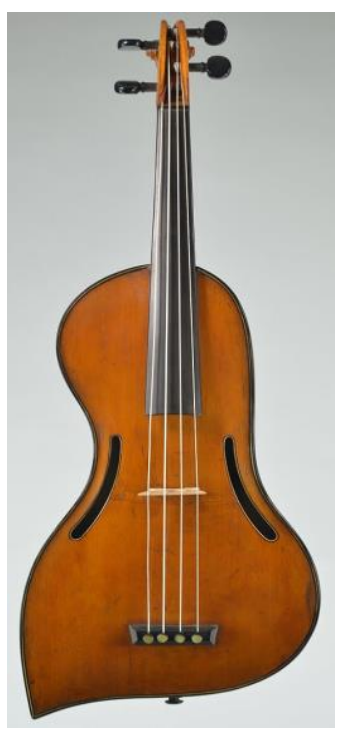

Fig 1. Chanot violin

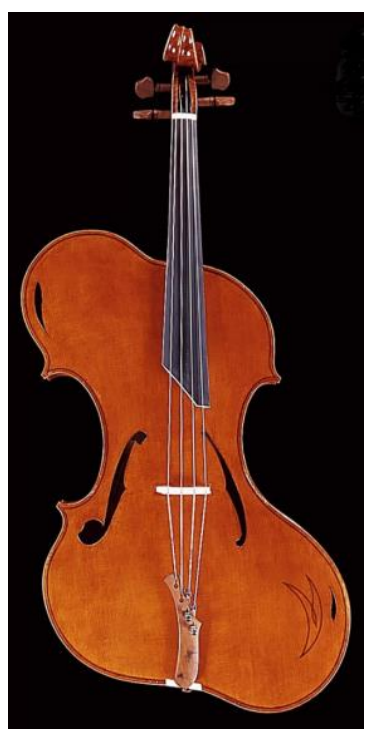

Fig. 2. Rivinus viola.
In the $20^{\text {th }} \mathrm{C}$ the most well-known and outspoken exponent of the ergonomic violin has been American, David Rivinus, now retired. Rivinus' string family instruments were the subject of shock and horror when they first arrived on the concert stage in the 1990's. The instruments that Rivinus has designed usually do not look like traditional instruments, but have lopsidedness and asymmetry more befitting a Dali painting. 
The extremely different shapes of these instruments have caused considerable controversy in the concert-going musical world. In a 2013 press release Rivinus stated: "Player injuries among violists and violinists are at epidemic levels. For the last two decades I have worked hard to address these concerns, specializing in the problems of neck, back, shoulder, elbow and hand pain. I have developed three models of viola and violin, all designed to bring the string player significant relief and, because the instruments do not exacerbate existing conditions, they assist the player to slowly heal" [13].

The Rivinus instruments are usually judged to be good instruments but not on the same level as a Stradivarius or high-end modern violin or viola. They allow injured musicians to heal so that they can continue to be employed, and practice. This would also help to prevent anxiety and depression that would aggravate the plight of injured players. If string players had originally learnt their craft on such instruments then they may never have become injured in the first instance.

Today, Rivinus' models are still highly sought after instruments mainly by injured musicians. They have developed a cult status given the fact that David Rivinus is no longer making these ergonomic tools. One question that arises is whether or not providing a cutaway body and a built-in chin rest soundboard removes all the dangers of playing a traditional viola? For decades, the modern guitar has incorporated a cutaway section to allow easy access to the upper frets. However, guitarists are still being injured - not strange given the fact that these upper frets are seldom played in most guitar music. Thus, is it the shape of the viola or the contorted positions that modern concert players have chosen to adopt? Or perhaps it is a combination of design and chosen technique?

Violin players tend to adopt the very high playing position with the left arm, leading to an elevated right arm and shoulder that supports the bowing hand [14]. If you add the unnatural chin displacement, both sides of the body can easily be injured due to these requirements. A colleague of mine suggested that a non-straight, angled bow would allow the right arm to be lowered, reducing the stress on at least the right side of the body. Curved bows certainly have been made but their use was aimed playing polyphonic chord music. The ergonomically angled bow has yet to be realized.

\section{RE-DESIGNING THE GUITAR}

Guitars are probably the most varied of all musical instruments manufactured in a large variety of shapes, scale lengths and styles, such as acoustic, classical, archtop, electric, and resonator. Injuries can affect players of any type of guitar, with the classical guitar being the design that has been most resistant to change of shape. It is possibly the most evolved however, in terms of acceptable contemporary high-tech materials, such as carbon-fibre, aramid papers like Nomex and Kevlar, and construction alternatives [15].

The ergonomic electric guitar properly starts with American Steve Klein in the mid 1990's who observed that when guitarists practice they tend to rest the guitar body on their right leg, allowing the guitar neck to drop, thus lowering the player's left shoulder and arm. This did not occur when guitarists used a strap because the strap held the guitar at an upright angle. But when guitarists practised they did so sitting down for most of the time.

Thus, Klein designed a guitar that balanced evenly on the right leg at an approximate 45 degree angle allowing the guitarist to sit with both feet flat on the floor, with no twists of the torso and no left shoulder stoop. In order to remove weight from the headstock, Klein placed the tuners on the body making the instrument totally headless thus producing less weight for the left hand to manage. Being smaller than a typical electric guitar also meant it was lighter and less prone to contribute to shoulder soreness if a strap was used.

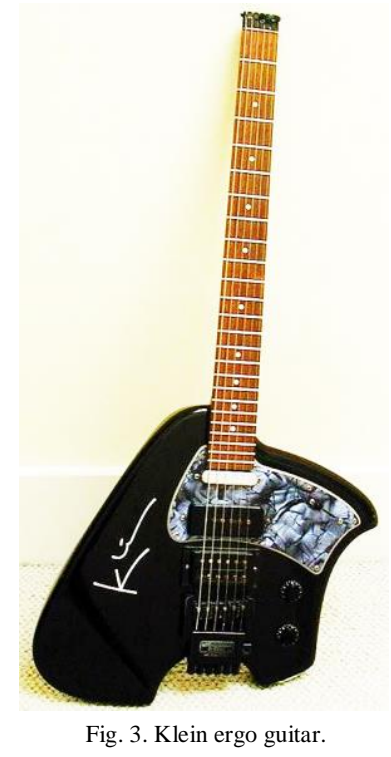

The popularity of the Klein ergonomic electric guitar has subsided over the years, to be taken up by a few dedicated custom luthiers who are specializing in variations upon this theme.

It should be noted that the Klein electric was not principally played by injured guitarists in the same way that the Rivinus instruments were. The Klein design embodied a set of principles that had less than mass appeal, but make a good deal of sense to small sections of the luthier community in 2017. The idea that the guitar should be lightweight as opposed to heavy, that form should follow function (not tradition), and that the guitar should be optimally balanced are concepts that have mercurial appeal for the buying public. Most guitars are objects of desire because they are played by guitar heroes, look cool and have certain brand names emblazoned on their headstocks.

Ergonomic principles have been incorporated into the designs of a few steel string acoustic and archtop makers. By mimicking the Klein treble body cutaway on a hollow-bodied guitar a similar 45 degree playing angle can be achieved. The resulting guitars however are asymmetrical and look even more unusual than the original Klein guitars since they are larger and look more unwieldy. In fact, they do not really look like guitars and are viewed as gimmicks, or unnecessary to the purist. Unfortunately, these purists include most of the luthier community who have worked solely on reproducing vintage and traditional designs. 


\section{The COMPuter AnAlogy}

In the 1980's there was an inexplicable Australian surge in the number of cases of RSI in a variety of workplaces. Strangely this surge in cases of RSI was not observed in other countries apart from Australia. The resultant research on the pain of fingers, wrists, hands, arms, and necks revealed a perplexing problem. Early researchers thought that RSI was a form of mass hysteria because medical science was unable to determine why so many Australians, especially females, were afflicted [16], [17]. Eventually the medical community realized that RSI was in fact a suite of different ailments that included carpal tunnel syndrome, tenosynovitis, focal dystonia, tendonitis, myalgia, bursitis, ganglions, and tension neck syndrome. Over time, the use of mainly ergonomic prevention lessened the risk of RSI and the epidemic in Australia was halted. The so-called rise and fall of RSI as a serious occupational hazard has been described as an outcome of any single or combination of factors - ergonomic, medical, psychosocial and legal - leading to an informed Australian society, which is no longer so badly afflicted [18].

The development of the medical model of RSI at this period in time has definite application to injuries sustained by musicians. A common observation was that very sensitive, fast keyboards in the 1980s allowed typists to type faster than they ever could on older typewriters. The increase in speed meant that workers were actually performing more keystrokes than ever before, thus facilitating the risk of microtraumas in the associated soft tissues [19]. The solution was to slow the typist down by forcing them to press the keyboard keys further down and adding more resistance to the keys. The same process occurs when a musician overuses a hand or wrist. They create microtraumas that cannot be seen by doctors and they are cumulative if the musician does not rest their body. Small aches and pains become a crippling disability if the musician does not stop their activity and allow themselves to heal. Making the instrument a bit harder (or easier) to play might be a useful intervention here.

Another medical hypothesis was that blood flow to certain muscles was altered by continually overusing one set of muscles and underusing another set of muscles. By continually using the same keyboard or tool or device the worker was causing arterial blockages, which over time could cause tissue damage and pain. The corollary for musicians is an obvious one - regular static practice in the one playing position might also occasion arterial blockage and pain. The solution for a musician is to change playing positions as much as possible to use different sets of muscles each time.

One of the most significant ergonomic factors were awkward, unnatural postures that workers held for long periods of time. The ergonomic model predicted that any mismatch between body dimensions and various tools would always lead to these awkward postures. In the musical context, the standard size of guitars is a possible problem for those musicians whose anatomy is different to the supposed norm. Weaker hands, or wrists, and shorter stature, arms, or fingers can directly lead to RSI problems if the musician continues to play the standard-sized instrument for any extended period of time. Obviously female upper limb anatomy is not as resilient as male anatomy leading to greater risks for female workers and also musicians.

\section{A LUTHIER's PERSPECTIVE}

Being a luthier and collector has meant easy access to hundreds of instruments over the years. While selling my guitars is a regular occurrence, my personal collection numbers over 30 instruments of all descriptions, styles and brands. Each guitar is slightly different in terms of action, feel, strings and playability. My habit is to seldom play the same guitar for more than a day or two. The different instruments are appropriate because of diversity in terms of styles of music and my appreciation of the various sonorities of the numerous instruments in my arsenal.

This situation is very different to the guitarist who owns perhaps a single guitar and uses it every day as their practice and performance tool. This particular guitarist is continually using the same posture, same string resistance, and same scale length with the same muscles and tendons. Unfortunately, this is exactly the formula for developing an overuse injury.

A possible solution for at-risk musicians is to change instruments as much as possible. Jazz guitarists could use easier to play nylon string guitars, classical players could use a shorter scale guitar, acoustic players could change to a lighter strung electric guitar. The fingerstyle player could start to use a plectrum, the plectrum player could use their fingers. That is, the guitarist needs to actively stop overusing the exact same postures and body parts. Different brands of guitars by their very nature feel quite different and force the musician to use different postures and body parts. Even very small changes may reduce the risk of overuse and RSI.

An innovative treatment for RSI is the use of Chinese medicine, which I have used for decades. Apart from acupuncture, there exists a herbal concoction that martial artists frequently use to heal their fingers, hands and forearms when they practice kung fu by hitting the wooden dummy. This concoction is variously called dit da jow or iron palm medicine and actually works to relieve pain and cure inflammation, including RSI.

The guitarist habit of sitting for long hours to practise repertoire needs to be reconsidered. This is certainly not necessary because guitar straps can be used to stand and practise. Classical guitarists have an array of devices that allow the guitar to be elevated on their left legs, but there is a more radical solution employed by Australian classical guitar virtuoso, Tom Ward. He uses a monopod to allow standing and performing when he busks around the world. This posture frees his whole body and resembles the philosophy behind computer stands that allow typists to stand instead of sitting for extended hours. While Tom looks more like an acoustic bass player, his standing posture attracts attention, gives him freedom of movement, and protects him from possible injury.

A good alternative style of guitar is the Gibson thinline line of semi-hollow bodied guitars with a body join at the $19^{\text {th }}$ fret instead of the more usual $14^{\text {th }}$ fret on acoustic and archtop jazz guitars. This one change means that the player has to extend their fretting arm changing the angles of all the left side body parts. This could be a useful alternative for jazz players who constantly use closer to the body necks. Another choice could be the classical guitar that has a body join at the $12^{\text {th }}$ fret, making life a bit easier in terms of fretting ability.

One of my current projects is a very short scale 
lattice-braced classical guitar because my practice of playing transcriptions by Astor Piazzola hurts my left hand fingers and hand due to the large stretches involved. Instead of a scale length of $650 \mathrm{~mm}$, the new guitar is $615 \mathrm{~mm}$ allowing me to comfortably stretch the required five frets. However most of the luthier community in Australia continue to build classical guitars of $650 \mathrm{~mm}$, with some using 640mm. Custom instruments below this size are often thought to be too short and unsuitable for a concert performance. My finished instrument sounds wonderful, and does not suffer from being shorter than usual.

The belief that all instruments are for future concerts or gigs is simply a myth that luthiers and the buying public need to resolve. The vast majority of guitars (and violins) will never be played by soloists in concerts. Yet, other than cheap three-quarter sized instruments, beginner guitarists have no other choice except to purchase concert-sized instruments. This probably results in many children and some adults having to painfully stretch their fingers to learn their new instruments. How many learners have given up music because they initially learnt on instruments that were difficult to play or did not fit their anatomy? Moreover, how many guitarists persist with playing such instruments that will eventually result in injury?

\section{Conclusions}

The epidemic of RSI in the white collar workforce has been stopped because managers admitted that the injury-causing keyboards, desks, monitors and tools were possible risks that employees needed protection from. Organisations were previously paying out large compensation sums and were forced to take action in the late $20^{\text {th }} \mathrm{C}$. However there is no equivalent compensation for those victims of RSI injury in the musical world. Such victims are being hurt by their own possessions, their own static postures, and their own techniques.

As long as players value traditional instruments and continue to play and overuse their body parts, some people will continue to become injured. This is an inevitable hazard of playing any kind of instrument, but especially risky for guitar players and string family instrumentalists.

The risk factors presumably increase if a player has body parts that are a bit shorter, smaller or weaker than the average player. This is when a mismatch between anatomy and a concert-sized instrument becomes a liability for some musicians.

As a musician who has experienced this process, I have discovered strategies to assuage my symptoms, and prevent them from recurring. However, the luthier community and most players themselves are not really in touch with this process of tradition, design, pain and injury.

Perhaps it should be the schools, teachers and parents who first expose their children to these dangers, who need to be aware of the myths and traditions surrounding guitars and violins. Their mantra should be that an instrument should fit the player, not the other way around. And let us not forget the luthier. It is not enough for luthiers to create excellent sounding instruments that inspire people to play music. The luthier should also do their best to keep their players safe.

\section{REFERENCES}

[1] N. A. M. Kutty, M. A. R. Jabbar, and S. S. Xian, "Prevalence and risk factors of playing-related musculoskeletal disorders among string instrument players in Malaysia," Indian Journal of Physiotherapy and Occupational Therapy-An International Journal, vol. 11, no. 1, pp. 64-69, 2017.

[2] C. Fritz, J. Curtin, J. Poitevineau, P. Morrel-Samuels, and F. Tao, "Player preferences among new and old violins," in Proc. the National Academy of Sciences of the United States of America, 2012, vol. 109, pp. 760-763,

[3] R. Johnson and D. Boak, Martin Guitars: A History, Milwaukee, WI, 2008.

[4] J. L. Romanillos, Antonio de Torres, Guitar Maker: His Life and Work, Shaftesbury, Element Books, Dorset, 2007.

[5] M. Darnton. Wood. [Online]. Available: www.darntonviolins.com/violinmagazine/book/wood.pdf

[6] H. J. Fry, "Overuse syndrome in musicians: Prevention and management," The Lancet, vol. 2, no. 8509, pp. 728-731, 1986.

[7] ibid.

[8] E. Krause. (2015). How many people in the world play guitar. [Online]. Available:

https://www.quora.com/How-many-people-in-the-world-play-guitar

[9] J. Horvath, Playing (Less) Hurt: An Injury Prevention Guide for Musicians, Hal Leonard Corporation, Milwaukee, WI, 2010.

[10] B. Paull and C. Harrison, The Athletic Musician: A Guide to Playing Without Pain, Scarecrow Press, Maryland, 1997.

[11] R. Saunders, R. Astifidis, S. L. Burke, J. Higgins, and M. A. McClinton, Hand and Upper Extremity Rehabilitation: A Practical Guide, Elsevier Health Sciences, St Louis, MI, 2015.

[12] Q. Whitney, American Luthier: Carleen Hutchins - the Art and Science of the Violin, Lebanon, NH: University Press of New England, 2016.

[13] L. Niles. (2013). Ergonomic violas: A look at the Rivinus Pellegrina. [Online]. http://www.violinist.com/blog/laurie/20134/14618/

[14] G. F. de Souza Moraes and A. P. Antunes, "Musculoskeletal disorders in professional violinists and violists: A systematic review," Acto Ortopedica Brasileira, vol. 20, no. 1, pp. 43-47, 2012.

[15] R. Archee, "The Australian school of Lutherie: Origins and achievements," International Journal of Humanities and Social Sciences, vol. 4, no. 1, pp. 101-107, 2014.

[16] W. Hall and L. Morrow. "Repetition strain injury: An Australian epidemic of upper limb pain," Social Science \& Medicine, vol. 27, no 6, pp. 645-649, 1988.

[17] S. Kiesler and T. Finholt, "The mystery of RSI," American Psychologist, vol. 43, no. 12, 1988, pp. 1004-1015.

[18] M. Grimshaw, "The rise and fall of RSI: Competing models of causation and the current debate," British Journal of Hand Therapy, vol. 10 , no. 3-4, 2005 .

[19] S. Pheasant, "Repetitive strain injuries," Ergonomics, Work and Health, UK: Macmillan Education, pp. 77-97, 1991.

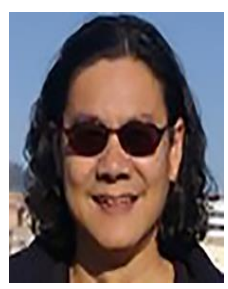

Ray Archee is an Australian academic, journalist, luthier and guitarist. He has a Ph.D in communication (Charles Sturt University, Bathurst, NSW), an MA (Psych) (University of Sydney), a Diploma in adult education (ITATE, Sydney) and has been a pioneer in the area of blended learning. He was also president of the Society for Technical Communication (Aust branch) and has won a national teaching award in 2011.

His current position is a lecturer at Western Sydney University, Sydney, Australia. The making of guitars has been his passion for the past 14 years with the majority of his output being archtop instruments. His guitars are played by leading jazz players in Australian and the USA. Dr Archee is the lead author of the popular textbook, Communicating as Professionals, with a 4e currently being written. Research interests include blended learning, intercultural communication, mediated communication and guitar making. 